\title{
FEMINISMO, EXPERIENCIA Y REPRESENTACIÓN
}

\author{
POR \\ NELLY RICHARD \\ Revista de Crítica Cultural \\ Santiago - Chile
}

El feminismo ha reaccionado divididamente a la incorporación de la teoría como instrumento de formación y lucha intelectual para las mujeres. Los movimientos feministas más directamente vinculados al activismo social, suelen considerar la teoría como algo sospechoso de reproducir las condiciones de desigualdad opresiva ligadas a una "división del trabajo" que opone - jerárquicamente - el pensar al hacer, la abstracción de los libros a la concreción de la vida material, la especulación mental al contacto físico con la realidad diaria, la clase media intelectual al mundo popular, etc. Muchos grupos feministas han generalizado el lugar común de que las mujeres deben combatir toda intelectualización por juzgarla siempre cómplice de la alianza falocrática entre el poder de la razón y la razón como poder. La teoría sería - para estos grupos - un discurso de autoridad culpable de repetir la censura mantenida durante siglos por el dominio conceptual del Logos (masculino) sobre la cultura del cuerpo y del deseo que asocia naturalmente lo femenino a lo subjetivo y a lo afectivo, al yo personal. Pese a tales desconfianzas, las mujeres han desarrollado en la escena cultural más reciente un trabajo intensamente teórico que entra en ardua competencia intelectual con la producción de conocimiento habitualmente situada bajo contrato masculino. Pero esta producción teórica lleva inscrita la marca predominante del contexto internacional que más fuertemente la sustenta y la organiza a través de su cadena de universidades y series editoriales que hacen circular los discursos desde los centros de validación metropolitana hacia la semi-periferia latinoamericana.

La acentuación metropolitana de la teoría feminista internacional es percibida conflictivamente por quienes se ubican en los bordes inferiores de la cartografia del poder transcultural, ahí donde se generan diversas reacciones de oposición y resistencia a su predominio conceptual y académico-institucional. La forma que toman algunas de esas reacciones reproduce indirectamente ciertos conflictos existentes entre dos categorías habitualmente en disputa dentro del campo de la reflexión feminista: experiencia (vivencia y autenticidad) y representación (forzamiento teórico-discursivo).

Quisiera dar una vuelta alrededor de la categoría de "experiencia" tensionándola con las categorías de "identidad", "diferencia", "texto" y "representación", y comentar a la vez los valores y usos de esa categoría referida a la perspectiva latinoamericana. 


\section{VIVENCIA, TEORÍA Y PRÁCTICA CRÍTICA}

Partamos por preguntarnos cúal es la necesidad — para las mujeres y el feminismo— de insistir en la importancia de la teoría.

Sabemos que el lenguaje, al nombrar, recorta la experiencia en categorías mentales, segmenta la realidad mediante nombres y conceptos que delimitan unidades de sentido y de pensamiento. La experiencia del mundo que verbaliza el lenguaje depende del orden semántico que moldea esa experiencia en función de un determinado patrón de intelegibilidad y comunicabilidad de lo real y de lo social. El modo en que cada sujeto se vive y se piensa está mediado por el sistema de representación del lenguaje que articula los procesos de subjetividad a través de formas culturales y de relaciones sociales. El signo "hombre" y el signo "mujer" también son construcciones discursivas que el lenguaje de la cultura proyecta e inscribe en la superficie anatómica de los cuerpos disfrazando su condición de signos articulados y construidos tras una falsa apariencia de verdades naturales, ahistóricas: "Hemos sido obligados, en nuestros cuerpos y en nuestras mentes, a corresponder, rasgo por rasgo, a la idea de naturaleza que se nos ha establecido". ${ }^{1}$ Nada más urgente entonces para la conciencia feminista que rebatir la metafísica de una identidad originaria - fija y permanente - que ata deterministamente el signo "mujer" a la trampa naturalista de las esencias y de las sustancias. Y para cumplir con dicha tarea, la crítica feminista debe tomar prioritariamente en cuenta el lenguaje y el discurso porque éstos son los medios a través de los cuales se organiza aquella ideología cultural que pretende volver los signos de identidad fijos e invariables: "la tarea no es simplemente cambiar el lenguaje, sino examinar el lenguaje en sus supuestos ontológicos, y criticar esos supuestos en sus consecuencias políticas", 2 ya que son ellos los que deliberadamente confunden hecho (naturaleza) y valor (significación) para frustrar todo impulso transformativo haciéndonos creer que "la biología es el destino".

La teoría es lo que forma consciencia acerca del caracter discursivo de la realidad en cuanto realidad siempre intervenida por una construcción de pensamiento que la designa y por una organización de significados que la nombra. Pero la teoría es también lo que le permite al sujeto transformar esa realidad dada como natural al abrir los signos que la formulan a nuevas combinaciones interpretativas capaces de deshacery rehacer sus trayectos conceptuales, de desordenar los marcos prefijados de comprensión y de reinventar nuevas reglas de intelegibilidad de lo naturaly de lo social. Para el feminismo, renunciar a la teoría sería privarse de las herramientas que nos permiten comprender y modificar a la vez el sistema de imágenes, representaciones y símbolos, que componen la lógica discursiva del pensamiento de la identidad dominante. Sería contribuir pasivamente a que sus mecanismos significantes permanezcan incuestionados.

La insistencia en el carácter semiótico-discursivo de la realidad ha sido uno de los puntos más trabajados por el feminismo teórico que subraya así el valor construido(representacional) de las marcas de identidad "masculina" y "femenina" que la cultura sobreimprime sobre los

\footnotetext{
'Monique Wittig citada por Judith Butler, "Variaciones sobre sexo y género" en Teoria Feminista y Teoría Crítica (Valencia: Edicions Alfons el Magnánim, 1990) 202.

2 Judith Butler, op. cit., 210.
} 
cuerpos "hombre" y "mujer", obligándolas al calce anatómico para justificar —sustancialistamente - la fijeza de las marcas de identificación sexual. La demostración de cómo la identidad y el género sexuales son "efectos de significación" del discurso cultural que la ideología patriarcal ha ido naturalizando a través de su metafísica de las sustancias, es útil para romper con el determinismo de la relación sexo ("mujer")—género ("femenino") vivida como relación plena, unívoca y transparente. Al movilizar la noción de "género" a través de toda una serie de desmontajes teóricos que muestran cómo dicha noción ha sido modelizada por convenciones ideológico-culturales, la crítica feminista nos permite alterar dichas convenciones reelaborando nuevas marcas de identificación sexual según combinaciones más abiertas que las antes seriadas por la norma de socialización dominante.

La complejidad de tales desmontajes teóricos ha sido asumida por el feminismo teórico de tendencia postestructuralista que se ejerce principalmente en el mundo universitario euronorteamericano. Entre quienes figuran como lo "otro" y las "otras" de esa dominante academicista metropolitana, han surgido enérgicas reacciones destinadas a salvar la categoría de "realidad" y de "experiencia" de los peligros a los que conduciría esa postura de hipertextualización del cuerpo y de la sexualidad: si lo real -como lo profesa el desconstruccionismo más radical- es un puro artefacto discursivo, si el signo-mujer no tiene más existencia que la lingüística, si la diferencia sexual es un constructo enteramente desligable de la corporalidad biológica, si no hay una exterioridad al discurso donde comprobar y denunciar la violencia material del poder masculino, entonces: ¿qué denuncia el feminismo?

Esta misma pregunta trasladada al escenario latinoamericano cobra aquí una renovada — irritada - vigencia ya que las condiciones materiales de explotación, miseria y opresión, de las que se vale el patriarcado para redoblar su eficacia en tramar la desigualdad en América Latina nos exigiría, según muchas feministas, más acción que discurso, más compromiso político que sospecha filosófica, más denuncia testimonial que arabescos desconstructivos.

La postura más simétricamente opuesta a la hipertextualización de lo sexual elaborada por el feminismo "deconstructivo" es la que sostiene el feminismo "esencialista" que "asume(n) que la experiencia no mediada por más teoría es la fuente del verdadero conocimiento"3 que nos garantizaría la "autenticidad" de lo femenino, su verdad primordial. La "experiencia" — en oposición a la "representación" - adquiere en estos casos el valor de una categoría pre-discursiva o extra-discursiva, de una realidad que no pasa por la mediación simbólica del concepto. La "experiencia" sería la base material-corporal que sustenta un conocimiento vivenciado desde la naturaleza (cuerpo) o desde la biografía (vida): un conocimiento no mediatizado por la ideología de la razón, un conocimiento in-mediato.

La revalorización de la "experiencia" como reacción antiteoricista del feminismo esencialista ha buscado invertir el sistema conceptual de la oposición logocéntrica gobernada por la jerarquía masculina de lo razonante, lo mental, lo inteligible que ha reprimido lo sensible, lo físico, lo afectivo e intuitivo, para privilegiar ahora - a favor de las mujeres - lo vivido (lo dado, lo espontáneo: lo natural) por sobre lo teorizado (lo abstracto, lo construido: lo artificial).

\footnotetext{
${ }^{3}$ Kaplan y Coward citadas por Teresa De Lauretis, "La esencia del triángulo o tomarse en serio el riesgo del esencialismo" en Debate Feminista 2 (México, 1990) 83.
} 
Pudiera entenderse el reclamo contra los abusos del textualismo como la justa defensa de aquella materia o energía que siempre excede la palabra que nombra y rebasa el orden estrictamente conceptual de la razón lingüística con un excedente bruto, indominable. Defensa, entonces, de los residuos heterogéneos que no son nunca enteramente sintetizables ni formalizables por la teoría porque su materia - tumultuosamente compuesta de alteridad y negatividad - desborda la armadura lógica de la razón categorial. Pero el rescate que hace el feminismo antidesconstructivo de una materia no subordinada a la "dictadura del significante lingüístico" no va en esa dirección. Su reivindicación de una exterioridad-alteridad al concepto mediante palabras como "experiencia" o "corporalidad" insiste más bien en lo prediscursivo, en la plenitud originaria de una especie de continuum fusional que liga naturalmente cuerpo, experiencia y verdad, sin la armadura cognitiva ni el sostén interpretativo de un vínculo construido. En boca de ese feminismo, la fluidez corporal de la "experiencia" evocaría una zona de no-corte anterior a la estructura diferencial de vacíos y ausencias que produce el signo a través de la regulación nominativa y de la legislación sintáctica del lenguaje. La condición-límite de esa anterioridad al signo - acusado por las mujeres de fundar verbalmente la primera institución de la diferencia - sería el silencio, ya que recurrir a la lengua para nombrar obliga siempre al sistema diferencial de cortes, separaciones y oposiciones que formalizan el habla. La reivindicación del cuerpo como experiencia y verdad naturales de la feminidad desconfia de la palabra mediadora que corta, divide y sujeta. Pero, ¿ cómo transmitir el valor feminista de esa experiencia del cuerpo sin nombrarla? Nombrarla es pasar por la mediación simbólica y lingüística de la palabra que necesariamente rompe con la autopresencia natural de la cosa, pero no nombrar dicha experiencia es renunciar a comunicarla y a transformarla entonces en un significado colectivo de transformación política. Salir de esa disyuntiva requiere imaginar una experiencia del discurso suficientemente fluida para moverse entre las fronteras de lo lógico-categorial y de lo concreto-material; una experiencia impulsada por el ritmo interdialéctico de un tránsito entre estructura y bordes, entre sistema y residuos, entre código y márgenes desestructurantes, entre identidad y diferencia, pero sin re-positivizar la Diferencia como alteridad absoluta: "la alteridad absoluta es la identidad absoluta"4 si no trabaja una noción de diferencia que sea relacionalidad.

Hay un punto de coincidencia en el que el imaginario femenino del cuerpo-naturaleza y de la lengua-madre se refleja en la concepción tradicionalista del ser latinoamericano como pureza originaria, creando visiones cómplices entre el mito de lo "propiamente" femenino y de lo "propiamente" latinoamericano. El pensamiento cultural de América Latina ha largamente debatido su problemática de la identidad fundándose en la oposición entre lo racional y lo irracional, lo meditado y lo instintivo, lo artificial y lo natural, lo foráneo y lo auténtico: lo profundo (el ser) y la superficie de las apariencias (la máscara). Son muchos los textos que cifran el valor de la "identidad" latinoamericana en todo lo que resiste y se opone a la síntesis racional de la modernidad de Occidente, en todo lo vinculado al núcleo primitivo de un ethos cultural que sella una verdad "más ligada al rito que a la palabra" y "al mito que a la historia". ${ }^{5}$ El Logos de Occidente (consciencia, espirítu, historia, técnicas e ideologías)

\footnotetext{
${ }^{4}$ Drucila Cornell y Adam Thurschell, "Feminismo, Negatividad e Intersubjetividad" en Teoría Feminista y Teoria Crítica, 240.

5 Sonia Montecino en Madres y Huachos; alegorias del mestizaje chileno (Santiago: Cuarto Propio, 1991) 30 .
} 
representaría, según sus autores, el dominio masculino de un proyecto civilizatorio que se ha dedicado a reprimir sistemáticamente su otro lado más oscuro y salvaje (naturaleza, cuerpo, inconsciente, rito y mito) cuya naturaleza más viva se expresa en la oralidad femenina y popular: una oralidad que la máquina disciplinaria de Occidente ha asimilado con violencia colonial a la cultura del libro y a su modelo de lo blanco, letrado y metropolitano. Es cierto que el paradigma de autoridad de la "ciudad letrada" (Rama) trazado por la inteligencia razonante del conquistador se ha impuesto sobre la pluralidad etnocultural de cuerpos y lenguas domesticadas a la fuerza por el canon erudito de la palabra occidental. Pero lo de arriba (orden, razón y signo) y lo de abajo (des-orden, cuerpo, rito y símbolo) no son sistemas rígidamente enfrentados por un dualismo absoluto que los opone como totalidades definitivamente aisladas una de otra. Son registros culturales que se superponen y se mezclan localmente gracias a fuerzas transpositivas de desplazamiento y reabsorción de parte de los signos de la modernidad. Lo que precede y excede el Logos occidental como sustancia rebelde a su hegemonía culturizadora no permanece fijamente retenido y consignado en la dimensión originariamente pura(inalterable) del ser latinoamericano. Lo "propiamente" latinoamericano es un contenido que se recrea según diferentes conexiones simbólico-sociales que mueven localmente límites de inclusión/exclusión que separan y oponen entre sí lo propio y lo ajeno, lo superior y lo inferior, lo metropolitano y lo periférico. Estas múltiples interacciones de contextos resitúan lo dominante y lo subordinado (lo culto y lo popular, lo moderno y lo tradicional, lo blanco y lo no-blanco, lo masculino y lo femenino) en siempre nuevas y móviles correlaciones de poderes. Fijar para siempre lo femenino en la imagen del cuerpo-naturaleza de América Latina como territorio virgen (símbolo premoderno de un espacio-tiempo no contaminado por la lógica discursiva de la cultura del signo) deshistoriza el significado político de las prácticas subalternas (femeninas, latinoamericanas) al negarles la posibilidad de realizar las operaciones de códigos que reinterpretarán los signos de la cultura dominante según nuevos - y rebeldes - contratos de significación.

Varias líneas de investigación feminista reeditan esa oposición entre concepto (abstracción, teoría) y materia (concreción, práctica) cuando les toca referirse a las prácticas de mujeres en América Latina. No es sólo que "al hablar de crítica literaria feminista hispanoamericana" se refieren más bien "a su institucionalización académica norteamericana" porque "el gran volumen de esta producción intelectual sin duda está en Estados Unidos" concentrada en sus departamentos universitarios de Estudios de la Mujer. ${ }^{6}$ Se trata además de que el feminismo académico metropolitano tiende a proyectar en las prácticas de mujeres latinoamericanas el significado mítico de un cuerpo vivo cuya energía natural compensaría la frialdad abstractiva del pensar que caracteriza a la máquina de enseñanza e investigación universitaria de la metrópoli. Sabemos que la cultura internacional opera según un esquema de "división global del trabajo" "que le reserva el privilegio de la teoría a la académia metropolitana mientras la periferia latinoamericana descrita y analizada por esa teoría es vista como un simple campo

\footnotetext{
"Hernán Vidal, ed., "Crítica literaria feminista y derechos humanos" en Cultural and Historical Grounding for Hispanic and Luso-Brazilian Feminist Literary Criticism (Minneapolis: Institute for the Study of Ideology and Literature, 1989) 259.

${ }^{7}$ Fredric Jameson, Introduction en "Postmodernism; Center and Perihery", SAQ 3 (Duke University Press, 1993) 420.
} 
de práctica habitado por quienes viven la experiencia mientras el latinoamericanismo del centro elabora su debida conceptualización. Dicho de otra manera, hay una división del trabajo que "pone a Latinoamérica en el lugar del cuerpo mientras el Norte es el lugar de la cabeza que la piensa", razón por la cual "los intelectuales norteamericanos dialogan con otros intelectuales norteamericanos sobre América Latina, pero sin tomar en serio los aportes teóricos de los críticos latinoamericanos"8 para no tener que compartir con ellos el exclusivo privilegio de la conceptualización. También dentro del feminismo opera este ideologema del cuerpo (realidad concreta, vivencia práctica) que soporta la fantasía de una América Latina animada por la energía salvadora del compromiso social y de la lucha comunitaria, cuyo valor popular y testimonial es juzgado políticamente superior a cualquier elaboración teóricodiscursiva: "fuera de los ámbitos oficiales de una cultura centrada en la escritura y la disquisición filosófica, en el retazo de la arpillera se cuenta una experiencia personal con el hilo y la aguja para inscribir la memoria e hilvanar a la mujer en su dolor".' Esta reubicación de la mujer por el lado de la in-mediatez del hacer (vivencia, acción, experiencia) con sus emblemas domésticos del "cocer, bordar o cocinar" ${ }^{10}$ hace juego con laimagen de Latinoamérica y de las prácticas de mujeres latinoamericanas como lo otro radical de la academia norteamericana. Si bien es cierto que las batallas descolonizadoras, las luchas populares y las convulsiones dictatoriales en América latina han gestado tex to y conocimiento fuera del canon libresco, en los bordes informales y subversivos de la cultura extra-académica e institucional, emblematizar ese cuerpo de experiencias como laúnica verdad del feminismo latinoamericano (su verdad primaria y radical, por antidiscursiva) puede llegar a confirmar el estereotipo de una "otredad" romantizada — en tanto popular — por la intelectualidad metropolitana y dejar así intacta la jerarquía representacional del centro que sigue hegemonizando todas las mediaciones conceptuales del "pensar".

Pero no todo el rescate de la experiencia que hace el feminismo se confunde con el naturalismo del dato primario. Tomado en su dimensión yano ontológica sino epistemológica, el concepto de experiencia tiene el valor crítico de postular formas de conocimiento parciales, situadas, relativas al aquí-ahora de una construcción local de sujeto y de práctica que desmiente la fundamentación universalista de la generalización masculina. La revalorización de la experiencia afirma también la concreción material-social de una determinada posición de sujeto específica a un contexto particular de relaciones sociales contra la ideología del conocimiento universal (impersonal) que sustenta las abstracciones neutralizantes de la filosofía. El recurso a la experiencia (la persona en situación: subjetividad y contextos) merece entonces ser defendida contra la tesis de la cientificidad del saber objetivo como saber puro, sin marcas de determinación sexual, sin la huella de los conflictos que se desatan en torno a la legitimación y apropación del sentido. Pero hablar del sujeto de la experiencia como persona en situación y posición es hablar de "posicionamientos de sujeto" que suponen articular redes de enunciaciones para dialogar con la cultura e interpelar sus códigos de representación. "Experiencia" no sería entonces la plenitud sustancial del dato biográficosubjetivo que preexiste al lenguaje sino el modo y la circunstancia en las que el sujeto ensaya

\footnotetext{
8 "Jean Franco; un retrato", Revista de Crítica Cultural 11 (Santiago de Chile, 1995) 20.

${ }^{9}$ Lucía Guerra, La mujer fragmentada; historia de un signo (Santiago: Cuarto Propio, 1995) 31.

${ }^{10}$ Guerra, op. cit., 171.
} 
diferentes tácticas de identidad y sentido, reinterpretando y desplazando las normas culturales. La "experiencia" designaría entonces una zona políticamente diseñada a través de la cual rearticular procesos de actuación que doten a su sujeto de movilidad operatoria para producir identidad y diferencia como rasgos activos y variables.

Si trasladamos esta problemática al campo del feminismo latinoamericano, la defensa política de esta última categoría de experiencia designaría — para nosotras - la relación de contexto y de situación a partir de la cual elaborar formas locales de producción teórica. Tanto teorizar la experiencia (darle a ésta el rango analítico de una construcción de significados) como dar cuenta de las particulares experiencias de la teoría que realiza la crítica feminista en espacios culturales no homologables a las codificaciones metropolitanas, pasa por afirmar el valor táctico de un conocimiento situado: un conocimiento que, por una parte, se reconoce marcado por una geografía subordinante del poder internacional y que, por otra parte, reconvierte esa localización geográfica en una postura crítica donde el "contexto" es también lo que se opone a un cierto nomadismo postmodernista que lo deslocaliza todo sin cesar borrando los trazados de fronteras reales y desdibujando sus antagonismos materiales. La "experiencia" sería entonces el modo contingente y situacional a través del cual producimos teoría, reinscribiendo los signos culturales que circulan internacionalmente en juegos de contextos capaces de perturbar la división que traza la academia metropolitana entre latinoamericanismo (teoría, conocimiento) y Latinoamérica (vivencia, práctica).

\section{CRÍTICA DE LA REPRESENTACIÓN Y MULTIPLICACIÓN DE SENTIDOS}

Así como ocurre en el campo del discurso y de la teoría, el concepto de "experiencia" posee también —en el campo de la escritura - una larga historia de discusiones: ¿cómo vincular feministamente entre sí los términos: "lenguaje", "condición sexual", "experiencia de género" y "texto femenino"; ¿a través de cual estética o política textual de la diferencia reivindicar una posición de lenguaje no asimilable a lo masculino-general? Mientras un tipo de feminismo literario tiende a suponer como naturales las asociaciones de identidad que términos como "mujer", "escritura" y "femineidad" ponen en relación de contiguidad expresiva, otro tipo de crítica (la postestructuralista) considera que estas asociaciones deben ser desconstruidas para problematizar cada unidad de significado que la ideología naturalista tiende a afirmar como plena y transparente (por ejemplo, "identidad femenina").

Una de las primeras demostraciones teóricas ejecutadas por la crítica feminista puso de manifiesto que el lenguaje no es el vehículo impersonal - neutro y general- que postula la tradición masculina para defender la trascendente universalidad de su discurso maestro. Lo neutro de la lengua - su aparente indiferencia a las diferencias - enmascara el operativo de haber universalizado a la fuerza lo masculino como representante absoluto del género humano. Al desmontar la arbitrariedad de ese operativo de fuerza y su verdad englobante, el feminismo ha dejado en claro que la lengua no es el soporte neutral que dice el idealismo metafísico sino un material enteramente traspasado por el proceso de hegemonización cultural de la masculinidad dominante. Para una mujer, "tomar la palabra" es entonces ingresar a un universo de discursos mayoritariamente legislado por reglas masculinas, sancionado por un modelo de representación que devalúa lo femenino como categoría inferior y secundaria. El lenguaje, la escritura literaria y las normas culturales, llevan la huella de este operativo de 
forzamiento institucional que subordina los textos a paradigmas de apreciación y recepción dictados por una escala de valores sociomasculinos. La primera tarea de la crítica literaria feminista ha consistido en denunciar la maniobra impositiva que obliga a las mujeres escritoras a regirse por catalogaciones y homologaciones masculinas y en estimular modelos afirmativos y valorativos del "ser mujer" como experiencia diferencial y propia.

Pero, ¿en qué se particulariza la escritura femenina y en qué se diferencia de la escritura masculina? ¿Cómo definir los rasgos que singularizarían la escritura de las mujeres sin caer en la trampa del esencialismo que amarra sexo e identidad a una determinación originaria? ¿Podemos hablar - tan divisioriamente- de escritura masculina y femenina si el lenguaje creativo, la textualidad poética, son espacios privilegiados de desplazamiento y transferencia del yo en los que se amplían y se remodelan incesantemente las fronteras de la subjetividad cultural, desbordando así el realismo biográfico-sexual del sujeto "hombre" o "mujer"? Éstas son algunas de las preguntas que han animado el debate en torno al tema de la "escritura femenina" y a cómo traducir la conciencia y experiencia de lo no-masculino con palabras de mujeres (a-propiadas e inapropiables).

La crítica feminista derivada de la escena teórica francesa (Cixous, Irigaray, etc.) ha dado una respuesta onto-fenomenológica a esa pregunta por lo distintivamente femenino, ligando el texto a una vivencia de la corporalidad: se trataría de una escritura que deja fluir la materia corporal tradicionalmente censurada por el modelo logocéntrico de racionalización masculina y que, a través de una estética de los flujos libidinales, de lo que se desliza y circula eróticamente más acá y más allá de la barrera sintáctica del Logos, produce ritmo, carne y deseo. La lengua primigenia del cuerpo de la madre - del "cuerpo a cuerpo" con la madre (Irigaray) - actuaría como depósito sensorial y afectivo de vivencias cuya plenitud es anterior al corte producido por la estructura de vacíos, ausencias y pérdidas, a la que es condenada el sujeto por el aprendizaje de la lengua que opera una semiotización masculina de lo real. El re-encuentro con la lengua-madre a través de una experiencia corpórea les daría a las mujeres escritoras la oportunidad de expresar una subjetividad "auténticamente" femenina con una voz no mediada por la ley hablada de la representación masculina, anterior a sus nominaciones e ideologías. La "experiencia del cuerpo" femenino-materno como modelo natural de una feminidad originaria que la escritura debería rememorar y transmitir, la reivindicación de una presimbolicidad del cuerpo como zona anterior al corte lingüístico y a la legislación paterna del signo, han llevado a muchas feministas a re-esencializar el yo de la mujer bajo el sello mítico de una fusión originaria con la madre. Es cierto que lo pulsional-semiótico conforma un estrato de la subjetividad que los procesos de formación cultural tienden a reprimir o excluir. Ese estrato corporal debe ser liberado y potenciado como fuerza subversivamente contraria a la hegemonía totalizante del logos masculino que opone la razón al deseo, el concepto a la materia. Pero habría que desbloquear ese estrato pulsional sin recaer en la fantasía primigenia de un cuerpo anterior al verbo y a la representación ya que dicha imagen de un cuerpo pre-cultural corta el sujeto de toda posibilidad de rearticular discursivamente y de transformar críticamente los signos hablados por las instituciones de la cultura. Julia Kristeva había formulado la tesis de una experiencia del lenguaje en la que los dos bordes que orillan el habla —el borde inferior (femenino) de lo psicosomático y el borde superior (masculino) de lo lógico-conceptual-no son bordes rígidamente opuestos sino fronteras que se mueven interdialécticamente. La escritura surgiría precisamente de esa contradicción 
móvil entre pulsión y concepto, flujo y segmentación, que adapta formas construidas según la experiencia del lenguaje que decide realizar el sujeto. Sibien la mujer establece una relación privilegiada con lo somático-pulsional, con aquellos flujos indisciplinados que escapan al control normativo de la ley simbólica por estar ella situada en la frontera de la cultura donde más se vulnera ese control y esa sujeción, la valencia crítica de la relación entre mujer y transgresión no está garantizada a priori: ella nace de una dinámica de los signos orientada hacia la ruptura de las significaciones monológicas que puede ser compartida por autores masculinos si su práctica del discurso busca también fisurar el molde del concepto. Una postura como ésta rechaza la coincidencia natural entre determinante biológica (ser mujer) e identidad cultural (escribir como mujer) para explorar las brechas y descalces de representación que se producen entre la experiencia del género (lo femenino) y su puesta en escena enunciativa a través de recursos políticamente significantes: es la elaboración crítica de esta no coincidencia la que permite convertir lo femenino en la metáfora activa de "una teoría sobre la marginalidad, la subversión, la disidencia"ll que supere la determinante naturalista de la condición "hombre" o "mujer" y se piense como nexo a construir entre subjetividad minoritaria (lo femenino como borde sexuado de la representación hegemónica) y políticas del signo (lo femenino como articulador y potenciador de varias formas de transgresión de identidad).

La absolutización de la diferencia (lo no masculino como alteridad radical) profesada por ciertas tendencias feministas fue convirtiendo la identidad femenina en el reducto separatista de una identidad a interpretary defender mediante un contra-sistema de valoresy significaciones completamente aparte. La idea de un saber independiente que defiende la autonomía de la cultura de las mujeres en una dimensión paralela y alternativa a la de la cultura de los hombres, priva lo femenino de una comunicación más plural y dialógica con las múltiples tramas de la cultura. Lo masculino y lo femenino son fuerzas relacionales que interactúan como partes de un sistema de identidad y poder que las conjuga tensionalmente. Toda conformación de sentido es heterogénea e incluye un proceso intertextual que reune una diversidad de acentos aunque esta diversidad quede largamente silenciada por el reduccionismo unificador de las metanarrativas. Lo femenino es la voz paradigmáticamente reprimida por la dominante de identidad que sobrecodifica lo social en clave patriarcal, pero liberar esa voz no implica substraerla del campo de tensiones que la enfrenta polémicamente a lo masculino para aislarla en un sistema aparte que vuelve a excluir lo diverso y heterológico. El sueño de un cierto feminismo que idealiza un más acá (originario) o un más allá (mítico) del patriarcado donde encontrar un lenguaje puramente femenino, depurado de toda contaminación de poder masculino, hace de ese lenguaje una "a-topía": "una utopía, un refugio $\sin$ ley", ${ }^{12}$ un habla que se sueña enteramente fuera de los sistemas de dominación como si pudieramos imaginar un mundo translúcido, definitivamente libre de opacidades y resistencias. Si toda demarcación de identidad supone el afuera constitutivo de un "ellos" que se opone al "nosotros", no puede haber una cultura (de mujeres) "completamente inclusiva donde el antagonismo, la división

\footnotetext{
"Julia Kristeva citada por Toril Moi en Teoría literaria feminista (Madrid: Cátedra, 1988) 171.

${ }^{12}$ Julia Kristeva, "El tiempo de las mujeres" en Debate Feminista 10 (México, 1995) 357.

${ }^{13}$ Chantal Mouffé, "Feminismo, ciudadanía y política democrática radical" en Revista de Crítica Cultural 9 (Santiago, 1994) 56.
} 
y el conflicto"13 desaparezcan para siempre formando así un universo sin ningún "otro" que interrumpa la lógica cerrada de lo idéntico a sí mismo. El carácter polémico y controversial de los signos de identidad siempre envueltos en disputas y renegociaciones de fuerzas entre dominancia y subordinación nos dice que lo femenino es una categoría que debe ser permanentemente reinterpretada según la acentuación crítica que exigen las circunstancias de discursos en las que se mueve. Lo femenino no es, entonces, el dato - precrítico- de una identidad ya resuelta, sino algo a modelar y producir: una elaboración múltiple y heterogénea que incluye el género en una combinación variable de significantes otros para entrelazar diferentes modos de subjetividad y diferentes contextos de actuación. Esta concepción interactiva de la diferencia-mujer es sin duda la que mejor sirve a la reflexión del feminismo latinoamericano ya que permite pluralizar el análisis de las muchas gramáticas de la violencia, de la imposición y de la segregación, de la colonización y de la dominación, que se intersectan en la experiencia de la subalternidad. Si bien es cierto que la contradicción genérico-sexual posee sus propias reglas que deben ser desmontadas con instrumentos conceptuales específicos a la denuncia del patriarcado, es también cierto que "es inevitable (y deseable) que (...) en los países neocolonizados la subyugación de la mujer sea estudidada en términos de relaciones globales de poder que incluyan el dominio y la superexplotación de los recursos simbólicos, económicos y sociales". ${ }^{14}$ Para esto, hacen falta teorías lo más flexibles y abiertas posibles a la multiplicidad articulatoria de las diferencias: teorías para las cuales lo femenino no sea un término absoluto — retotalizador de los signos de la contradicción sexual— sino una red de significados en proceso y construcción que cruzan el género con otras marcas de identificación social y de acentos culturales. Estas marcas remiten en América Latina a una pluralidad disímil de voces y estratos de identidad que derivan de espacios y tiempos irregulares, de memorias y tradiciones híbridas. Sólo reinscribiendo lo femenino en un contexto de lecturas suficientemente múltiples e interactivas, es posible dar cuenta de la heterogeneidad de posiciones culturales que asumen los signos de identidad en América Latina donde "cohabitan diosas y dioses precolombinos, vírgenes y brujas, oralidad, escritura y otras grafias; voces indígenas, mestizas y europeas; retazos de máquinas sociales, rituales, semifeudales o burguesas; pero también dioses del consumismo, voces de la ciudad y de la calle, fragmentos de cultura libresca". 15

Los "dioses del consumismo" reciben ofrendas también de las mujeres escritoras cuyas obras son exitosamente promovidas por el mercado literario internacional que convierte hoy lo femenino y lo latinoamericano en la doble marginalidad ilustrativa de su diversidad de ofertas que traduce centro y márgenes a la misma lengua del pluralismo de mercado: "existe en la actualidad una demanda sin precedentes de obras literarias escritas por mujeres, particularmente de los textos que parecen reflejar, de una manera u otra, la 'experiencia' femenina". ${ }^{16}$ ¿Cuál "experiencia" de lo femenino cultiva el mercado literario internacional para que un público mayoritario de mujeres se reconozca tan familiarmente en sus universos

\footnotetext{
${ }^{14}$ Kemy Oyarzún, "Género y etnia; acerca del dialogismo en América Latina" en Revista Chilena de Literatura 41 (Santiago, 1992) 36.

${ }^{15}$ Oyarzún, op. cit., 35.

${ }^{16}$ Jean Franco, "Invadir el espacio público, transformar el espacio privado" en Debate Feminista 8 (México, 1993) 273.
} 
de referencia, en sus patrones de representación y en sus tipologías de personajes? La mayoría de estas obras festejadas por el mercado proponen una identificación positiva de las lectoras con imágenes femeninas que retratan significados de identidad previamente verbalizados por una sociología común de la mujer, como si existiera "una supuesta continuidad, lisa e ininterrumpida, entre realidad y experiencia, concepto y expresión, sexo y escritura": ${ }^{17}$ es decir, como si las obras sólo tuvieran por función revelar — temáticamente - una conciencia y experiencia del ser mujer tomada como referencia colectiva de significación ya definida y garantizada — estabilizada - antes que la articule (o desarticule) la práctica del texto. Segmentados por la mecánica distributiva del mercado que los circunscribe a categorías fácilmente manipulables (lo femenino, lo latino, lo juvenil, lo homosexual, lo étnico, etc.), los receptores de estas obras se ajustan redundantemente a la imagen de Lector Modelo que fabrica para ellos la industria cultural "con sagacidad sociológica y con un brillante sentido de la media estadística". ${ }^{18}$ Son obras que suelen reflejar una doble ilusión representativa: creen en una estética que le asigna a la obra la tarea de ilustrar temas o contenidos previamente articulados por el discurso social de tal manera que sean automáticamente reconocibles, y pretenden a la vez que estos temas y contenidos identifiquen a una clase homogénea de lectores que revalidarán su "sentido común" en la ilustratividad del estereotipo. Reconocimiento e identificación son las claves tranquilizadoras que comunican al lector con una matriz de significación donde lo legible nace de la absoluta y fija identidad entre significante y significado. Sin embargo, hay también textos que trabajan contra las reglas del mercado y que buscan contrariar ese modo pasivo de consumir significados transparentes, nunca problemáticos en su literariedad. Son obras que buscan romper ese calce identificatorio con representaciones de identidad preestructuradas y que llevan la relación estética entre subjetividad y lenguaje a planos de discontinuidad y de ruptura crítica del supuesto naturalista que plantea un sentido anterior a los recursos técnicos de su modelaje expresivo. De lo que se trata en los textos más perturbantes de esta nueva narrativa de mujeres (tomando como ejemplo la obra de la chilena Diamela Eltit), es de involucrar el lector en la experiencia de la significación como transcurso y producción de signos. Leer no sería entonces reconocer un sentido ya cifrado en la obra y transmitido por ella como resultado sino la actividad de recrear postulados de lectura a través de una red de enunciados ambiguos y plurales que descentra toda imagen de autoría/autoridad. Lo femenino podría designar ese vector de descentramiento significante que opera desde un margen cuestionador de la representación sexual y cultural, y que reflexiona sobre las retóricas formales, los cálculos ideológicos, las maniobras expresivas que utiliza el discurso hegemónico para disimular el contrato masculino que legitima su apropiación de la cultura. Ese "femenino" no es un contenido de identidad ya formado (anterior y exterior a su representación verbal) sino la posición crítica que consiste en interrogar los mecanismos de constitución del sentido y de la identidad, en llamar la atención sobre la materialidad discursiva de los mensajes que la ideología cultural dominante busca transparentar para hacernos creer que sus significados han sido fijados de una vez para siempre.

Ese "femenino" - rearticulado por la teoría feminista - operaría como un vector de cuestionamiento múltiple a las operaciones de la cultura que naturalizan -mediante

\footnotetext{
${ }^{17}$ Enrico Mario Santí, "El sexo de la escritura" en Debate Feminista 5 (México, 1994) 196.

${ }^{18}$ Umberto Eco, Lector in Fabula (Barcelona: Lumen, 1981) 82.
} 
condicionamientos, automatismos, programaciones y repeticiones - todo un régimen de significación así desestabilizado en su rutina. Es la acentuación teórico-política de esa función desestabilizadora — ampliada a varias gramáticas de la representación que se verían conjuntamente afectadas por ella - la que hace que "lo femenino" pueda servir de conceptometáfora para nombrar a "diferencias que confunden, desorganizan y vuelven ambiguo el significado de cualquier oposición binaria".19 masculino/femenino, identidad/diferencia, centro/periferia, etc. La doble marginalidad de la literatura femenina latinoamericana (doblemente inferiorizada por la centralidad del poder masculino y metropolitano-occidental) nos dice que "la urgencia política que acompaña el discurso crítico se acentúa au üun más" porque debe cumplir aqui una tarea doblemente descolonizante ("no sólo de liberación de prejuicios sexuales, sino también de mutilantes dependencias culturales"). ${ }^{20}$ De ser así, esa crítica debería aprender a combinar posiciones diferenciales en el ánalisis del sentido y sus regulaciones de poder para poder recorrer varias líneas de dominancia a la vezy deternerse en los cruces que amarrran secretamente una línea con otra. Debería ser capaz de poner al descubierto los intereses ocultamente concertados por la cultura hegemónica tras el supuesto de la transparencia neutral de los signos y del modelo de reproducción mimética que propicia el mercado a través de un consumo pasivo. Hacer que la posición "mujer" articule la lectura como un mecanismo activo que estimula al lector para que critique el sentido obligado y formule nuevos contratos de interpretación ahora favorables a la emergencia de subjetividades alternativas y disidentes, sirve los propósitos de un feminismo latinoamericano que se concibe como un feminismo no de la diferencia sino de las diferencias: un feminismo que postula múltiples combinaciones de signos y "transiciones contingentes" (Laclau-Mouffé) entre registros heterógeneos y plurales de identificación sexual, de participación social y de lucha cultural contra el menú conformista (pasivizante) de las indiferentes diferencias que promueve el pluralismo institucional y de mercado.

\footnotetext{
${ }^{19}$ Joan Scott, "Igualdad versus diferencia: los usos de la teoría postestructuralista" en Debate Feminista 5 (México, 1992) 104.

${ }^{20}$ Santí, op. cit., 195.
} 